This document is the Accepted Manuscript version of a Published Work that appeared in final form in The Journal of Physical Chemistry C, copyright @ American Chemical Society after peer review and technical editing by the publisher. To access the final edited and published work see dx.doi.org/10.1021/jp5005314.

\title{
Influence of molybdenum oxide interface solvent sensitivity on charge trapping in bilayer cyanine solar cells
}

Sandra Jenatsch ${ }^{a, b}$, Roland Hany ${ }^{a}$, Anna Veron ${ }^{a}$, Martin Neukom $^{c}$, Simon Züfle ${ }^{d}$, Andreas Borgschulte $^{e}$, Beat Ruhstaller ${ }^{c, d}$, Frank Nüesch ${ }^{a, b, *}$

${ }^{\text {a }}$ Laboratory for Functional Polymers, Swiss Federal Laboratories of Materials Science and Technology, Empa, Überlandstrasse 129, CH-8600 Dübendorf, Switzerland

${ }^{\mathrm{b}}$ Institute des Matériaux, Ecole Polytechnique Fédérale de Lausanne, EPFL, Station 12, CH1015 Lausanne

${ }^{\mathrm{c}}$ Fluxim AG, Technoparkstrasse 2, 8406 Winterthur, Switzerland

${ }^{\mathrm{d}}$ Zurich University of Applied Sciences, Institute of Computational Physics, Technikumstrasse 9, 8401 Winterthur, Switzerland

${ }^{\mathrm{e}}$ Hydrogen and Energy, Swiss Federal Laboratories of Materials Science and Technology, Empa, Überlandstrasse 129, CH-8600 Dübendorf, Switzerland

organic solar cells, cyanine dyes, CELIV, $\mathrm{MoO}_{3}$, tetrafluoropropanol, capacitance-voltage, current-voltage, interface, XPS 


\section{ABSTRACT}

Bilayer organic solar cells based on trimethine cyanine donor and $\mathrm{C}_{60}$ acceptor materials have been fabricated by coating the trimethine dye from solution on molybdenum oxide $\left(\mathrm{MoO}_{3}\right)$ anode buffer layer. The choice of deposition solvent drastically influences device performance, with 2,2,3,3-tetrafluoro-1-propanol (TFP) reducing the fill factor and power conversion efficiency of the device by $36 \%$ and $21 \%$, respectively, as compared to chlorobenzene. In the case of TFP, extraction of photogenerated charge carriers by linearly increasing voltage (photo-CELIV) and capacitance-voltage analysis revealed the formation of a hole trapping zone at the molybdenum oxide interface which is also responsible for the S-shape currentvoltage curve under white light irradiation. The transient charge extraction signal originating from trapped holes at the $\mathrm{MoO}_{3}$ interface could be clearly distinguished from the one relating to hole mobility in cyanine films using photo-CELIV measurements with varying delay times. 


\section{INTRODUCTION}

Performance of organic photovoltaic devices (OPV) fabricated by solution deposition of organic semiconductors relies on a plethora of factors such as substrate surface wetting, structure of the molecular assembly, film morphology, interface formation, to name only a few ${ }^{1}$. In polymer bulk heterojunction solar cells, only a finely tuned equilibrium between solvent ${ }^{2-4}$, co-additives ${ }^{5-7}$, and electrode work function ${ }^{8-10}$ leads to high efficiency devices with power conversion efficiencies (PCE) close to $10 \%{ }^{11}$. Small molecules have increased tendency to crystallize $^{12-15}$ and therefore the choice of solvent is crucial to obtain smooth homogeneous films ${ }^{16}$. In some cases crystallization is seeded at the interface between the donor and acceptor materials $^{17,18}$, while other works demonstrate the possibility to grow organic single crystals on patterned substrates ${ }^{15,19}$. Similar to polymers, solvent issues in small molecule solar cells impact the formation of phase separated donor and acceptor domains with mesoscopic dimensions $^{20-24}$. PCE recently culminated to $8 \%$ in single junction devices and $10 \%$ in tandem devices using the same junction ${ }^{24}$. Unlike bulk heterojunction solar cells, bilayer heterojunction device fabrication based on solution processing requires the use of orthogonal solvents ${ }^{23,25}$. This constraint can in some cases be relaxed, e.g. by using crosslinkable polymers ${ }^{26}$ or small molecules with detachable soluble groups ${ }^{27}$ as well as by combining both solution and vapor deposition $^{28,29}$.

Only few works have been dedicated to the effect of solvents on the electrode interface layers. Most of these studies concern the improvement of poly(3,4-ethylenedioxythiophene) poly(styrenesulfonate) (PEDOT:PSS) conducting polymer buffer layers using treatments with polar solvents ${ }^{30-34}$. Another work reports on solvent effects on thin metal front contacts of solar cells with inverted layer sequence. The solvent of the absorber blend was found to have a distinct impact on the stability of the initially deposited cathode layer consisting either of 
semi-transparent ultra-thin $\mathrm{Au}$ films or Au grid structures ${ }^{35}$. Finally, solvent cleaning of the substrate was proven to leave significant carbon contamination on the substrate ${ }^{36}$.

Here we investigate the influence of solvent in the fabrication of cyanine dye solar cells. This particular class of soluble semiconductor materials is characterized by a polymethine chain defining the cationic chromophore which most often is accompanied by a free counterion and forms an organic salt. As a consequence, cyanine dyes are highly soluble in polar solvents such as 2,2,3,3-tetrafluoro-1-propanol (TFP) and present good solubility in less polar solvents such as chlorobenzene (CB). In previous work, we showed that solvent and counterion determine structure formation in cyanine-fullerene blends via a liquid-liquid dewetting mechanism ${ }^{37}$. Due to morphological issues, PCE in these bulk heterojunction solar cells have always lagged behind bilayer heterojunction devices which recently reached a PCE of $3.7 \%{ }^{38}$. The effect of coating solvent was investigated for trimethine cyanine dye 1-ethyl-2-[3-(1ethyl-1,3-dihydro -3,3-dimethyl $\quad$-2H-indol-2-ylidene)-propen-1-yl]-3,3-dimethyl-3Hindoliumhexafluorophosphate (Cy3-P) using regular and inverted device architectures as well as different anode buffer layers. In devices with regular layer sequence, coating from TFP always resulted in lower fill factors as compared to $\mathrm{CB}$, while high fill factors were obtained for devices prepared from TFP with inverted structure ${ }^{38}$. Other works also noted that solution deposition from $\mathrm{CB}$ on PEDOT:PSS leads to strong S-shape and low fill factors, whereas deposition on $\mathrm{MoO}_{3}$ resulted in good current-voltage characteristics ${ }^{39}$.

In this work we unravel the striking difference in device performance observed when coating the cyanine layers on $\mathrm{MoO}_{3}$ from TFP and CB, respectively. The marked S-shape leading to a low fill factor is completely absent when using $\mathrm{CB}$ as a solvent for thin cyanine films. Using photogenerated charge-extraction-by-linearly-increasing-voltage (photo-CELIV) and capacitance-voltage measurements, we demonstrate that positive charge carriers are trapped close to the $\mathrm{MoO}_{3}$ interface in the case of TFP and show that there is negligible trapping in the case of 
CB. Numerical modeling is applied to confirm that such a trapping layer leads to an S-shaped current-voltage characteristic in cyanine $/ \mathrm{C}_{60}$ bilayer heterojunction cells. 


\section{EXPERIMENTAL}

Regular multilayer solar cells were fabricated using the structure: ITO/ $\mathrm{MoO}_{3} / \mathrm{Cy} 3-$ $\mathrm{P} / \mathrm{C}_{60} / \mathrm{Alq}_{3} / \mathrm{Ag}$ with the layer thicknesses presented in Figure 1. The layer thicknesses of Cy3$\mathrm{P}$ and $\mathrm{C}_{60}$ were varied in several experiments described in this work. The ITO coated glass substrates were subsequently cleaned in ultrasonic baths of acetone, ethanol, soap and distilled water. As a hole-extracting layer, $10 \mathrm{~nm}$ of $\mathrm{MoO}_{3}$ (Alfa Aesar, 99.9995\%) was deposited by sublimation in a vacuum chamber at a pressure $<10^{-5}$ mbar. 1-ethyl-2-[3-(1-ethyl-1,3dihydro-3,3-dimethyl-2 $H$-indol-2-ylidene)-1-propen-1-yl]-3,3-dimethyl-3 $H$-indolium $\quad$ hexafluorophosphate (Cy3-P) was synthesized in our laboratory, 2,2,3,3-tetrafluoro-1-propanol (TFP, Aldrich, 98\%) and chlorobenzene (CB, Sigma-Aldrich, 99.8\%) were used without further purification. The electron donor material Cy3-P was spin coated at $4000 \mathrm{rpm}$ from TFP or $\mathrm{CB}$, respectively, inside a nitrogen-filled glove box. Electron acceptor material $\mathrm{C}_{60}$ (SES Research, 99.5\%) and a $2 \mathrm{~nm}$ thick cathode buffer layer of tris-(8-hydroxyquinoline) aluminium $\left(\mathrm{Alq}_{3}\right.$, Sigma-Aldrich, 99.9995\%) were vapor deposited at a pressure $<10^{-5}$ mbar. Finally, Ag was evaporated through a shadow mask to define four solar cells with active areas of 3.1 $\mathrm{mm}^{2}$. The chemical structures of the active materials as well as the energy level diagram of the solar cell devices are shown in Figure 1, where energy values were taken from literature ${ }^{40,41}$. 


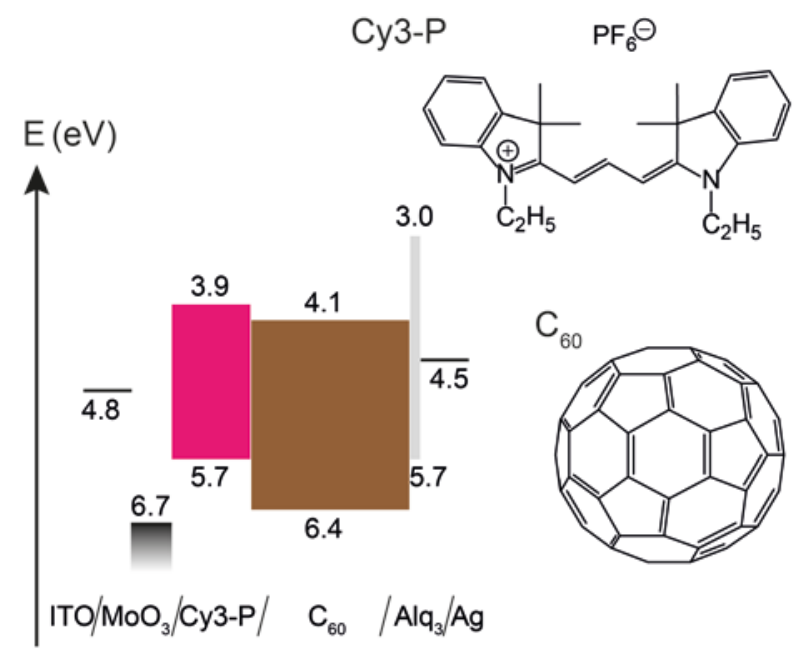

Figure 1. Left: Energy level diagram of the used regular device architecture $\mathrm{ITO} / \mathrm{MoO}_{3}(10$ $\mathrm{nm}) / \mathrm{Cy} 3-\mathrm{P}(20 \mathrm{~nm}) / \mathrm{C}_{60}(40 \mathrm{~nm}) / \mathrm{Alq}_{3}(2 \mathrm{~nm}) / \mathrm{Ag}$. Right: Schematic drawings of the chemical structure of the active layer materials.

Thickness measurements of Cy3-P films were performed by profilometry (Ambios XP1) on reference samples coated on glass. For thin layers with unknown thickness, absorption spectra were recorded (Varian Cary 50 UV-vis spectrophotometer) and the thickness was calculated from the optical density. A blank ITO coated glass substrate was used as reference for the absorption measurements. Incident photon-to-current efficiency (IPCE) was determined using a monochromator and a $300 \mathrm{~W}$ Xe lamp light source adjusted by means of an AM 1.5G filter. A calibrated Si-diode was used to measure the light intensity. Surface probe microscopy (SPM, Nanosurf Mobile S) was performed in tapping mode using silicon cantilevers (Mikromasch, Nanosensors TM).

Charge carrier mobility can be obtained by conventional time-of-flight experiments requiring that the dielectric relaxation time has to be longer than the transit time $\left(\tau_{\sigma}>t_{\mathrm{tr}}\right)^{42}$. Therefore, thick organic layers of several $\mu \mathrm{m}$ are needed which are difficult to achieve by spin coating. Here we used the charge-extraction-by-linearly-increasing-voltage (CELIV) technique, which 
allows obtaining charge carrier mobility in real thin film photovoltaic devices ${ }^{43}$. Since the organic semiconductors used in this work are insulators, charge carriers were first generated by a light pulse before being extracted by a triangular voltage ramp $A$ (photo-CELIV). This allows introducing a delay time between the end of the light pulse and the start of the voltage ramp in order to investigate recombination kinetics. From the peak position in the current response $\left(t_{\max }\right)$ the mobility can be calculated. Since we studied bilayer devices in this work, the analytical formula introduced by Juška et al. for single layer devices ${ }^{42}$ was adapted to account for the actual electric field through the cyanine layer, when applying the voltage ramp $A$ over the whole device:

$\mu_{C y 3-P}=\frac{2 d_{C y 3-P}\left(d_{C y 3-P}+\frac{{ }^{\varepsilon} C y 3-P}{\varepsilon_{C 60}} d_{C 60}\right)}{3 A t_{\max }^{2}} \cdot \frac{1}{\left(1+0.36 \frac{\Delta j}{j_{0}}\right)}$

where $d_{\mathrm{Cy} 3-\mathrm{P}}, d_{\mathrm{C} 60}$ are the active layer thicknesses and $\varepsilon_{\mathrm{Cy} 3-\mathrm{P}}, \varepsilon_{\mathrm{C} 60}$ the respective dielectric constants, $\Delta j$ the peak height and $j_{0}$ the capacitive current. Although this equation was derived assuming a uniform charge density through the device layer, we use it for the approximate analysis of a bilayer device, where the charge distribution may deviate from homogeneity. Device mobilities were averaged over 3 to 14 different devices and were consistent within $10 \%$ error, when not otherwise specified.

Capacitance-voltage $(C-V)$ measurements were performed by applying a DC offset voltage and a superimposed small oscillating signal (amplitude $70 \mathrm{mV}$, frequency $10 \mathrm{kHz}$ ) to the device. The frequency was kept constant and the applied DC offset voltage was varied. If the modulation amplitude is small enough, the device can be considered as linear at this working point and the impedance can be calculated from the measured current. The capacitance $C$ and the conductance $G$ were calculated according to $1 / Z=Y=G+\mathrm{i} \cdot \omega \cdot C$, where $Z$ is the impedance, $Y$ is the admittance and $\omega$ is the angular frequency. 
Photo-CELIV transients, impedance spectroscopy $(I S)$, current-voltage (I-V) and capacitancevoltage $(C-V)$ measurements were carried out using the PAIOS system ${ }^{44}$ in a nitrogen-filled glove box. All the measurements were performed subsequently in an automated way for each solar cell using the same contacts. For the photo-CELIV experiments the samples were illuminated by a $30 \mu$ s blue LED (Seoul Semiconductors Power LED blue, B42182) pulse with an intensity of $300 \mathrm{~mW} / \mathrm{cm}^{2}$ (peak intensity at $468 \mathrm{~nm}$ ). After a variable delay time $t_{\text {delay }}$ the photogenerated charges were extracted using a voltage sweep rate $A$, varied between 100 and $400 \mathrm{~V} \mathrm{~ms}^{-1}$. Prior to the voltage ramp, the applied voltage was iteratively set to $V_{\mathrm{oc}}$ (open circuit conditions) during the light pulse in order to avoid preliminary charge extraction. $I-V$ curves were recorded using the same blue LED at variable light intensity. The simulations were performed using the SETFOS software ${ }^{45}$ that has previously been used to extract organic solar cell parameters by combining steady-state and transient techniques ${ }^{46}$.

XPS surface analyses of Cy3-P films were performed in a modified VG ESCA Lab spectrometer with a base pressure below $10^{-9}$ mbar. The samples were inserted via an $\operatorname{Ar}$ glove box $\left(\mathrm{O}_{2}\right.$ and $\mathrm{H}_{2} \mathrm{O}$ pressure smaller than $1 \mathrm{ppm}$ and $0.1 \mathrm{ppm}$, respectively) directly connected to the spectrometer and transferred without exposure to air. XPS spectra were collected with a SPECS PHOIBOS 100 analyzer using a non-monochromated X-ray source (Al K- $\alpha$ : $1486 \mathrm{eV}$, $300 \mathrm{~W})$.

\section{RESULTS}

Cyanine solar cells with Cy3-P layer thickness of $20 \mathrm{~nm}$ were fabricated with regular layer sequence according to Figure 1. In order to investigate the role of coating solvent, TFP as well as $\mathrm{CB}$ were used for the fabrication. For thickness ranges up to $40 \mathrm{~nm}$, both solvents provide good film forming properties when using spin coating deposition. For films thinner than 20 $\mathrm{nm}$, however, wetting problems of less polar CB leads to non-continuous films which cause 
non-linear absorption behavior with dye solution concentration and rougher film morphology (supporting information, S1). The lack of control of cyanine film morphology in the case of $\mathrm{CB}$ is also held responsible for the rather large variation of open circuit voltage $\left(\mathrm{V}_{\text {oc }}\right)$ we have previously observed ${ }^{38}$; electrons in $\mathrm{C}_{60}$ have an additional recombination pathway with holes at the $\mathrm{MoO}_{3}$ interface. As inferred from Figure 2, the absorption spectra of $20 \mathrm{~nm}$ thick films only slightly depend on the coating solvent, and result in almost identical IPCE when implemented in OPV devices. However as already reported in previous work ${ }^{38}$, substantial differences are observed in the $I-V$ characteristics. Devices with active layer thicknesses of Cy3-P $(20 \mathrm{~nm}) / \mathrm{C}_{60}(40 \mathrm{~nm})$, where Cy3-P was coated from TFP exhibit a marked S-shape and correspondingly low fill factor, while those devices using $\mathrm{CB}$ as coating solvent always show high fill factors (Figure 3a). In both cells the short circuit current density $\left(J_{\text {sc }}\right)$ increases linearly with increasing light intensity. Even more pronounced is the difference in the photo-CELIV signal. While the cell coated from CB exhibits only a small overshoot, the one from TFP has a peak height $\Delta j$ that is comparable to the capacitive current $j_{0}$ (Figure $3 b$ ).

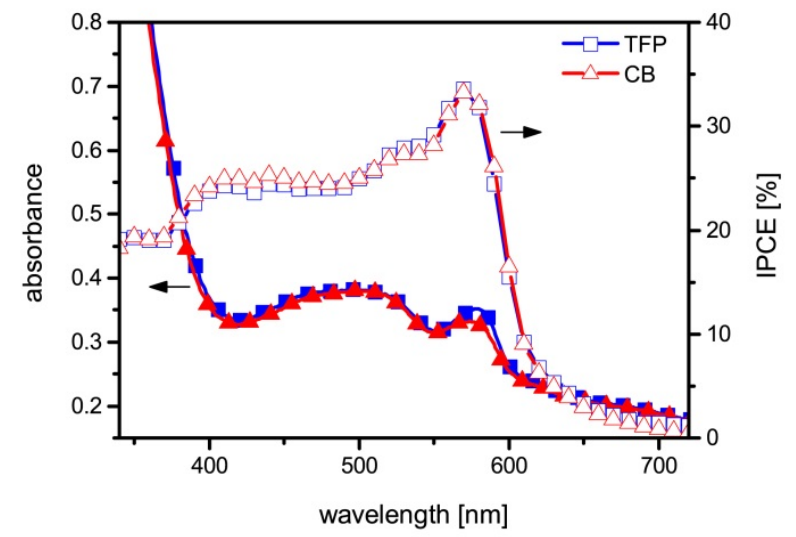

Figure 2. Absorbance (full symbols) and IPCE (open symbols) of a regular cell in which Cy3-P was coated from TFP (blue squares) or CB (red triangles) respectively. 

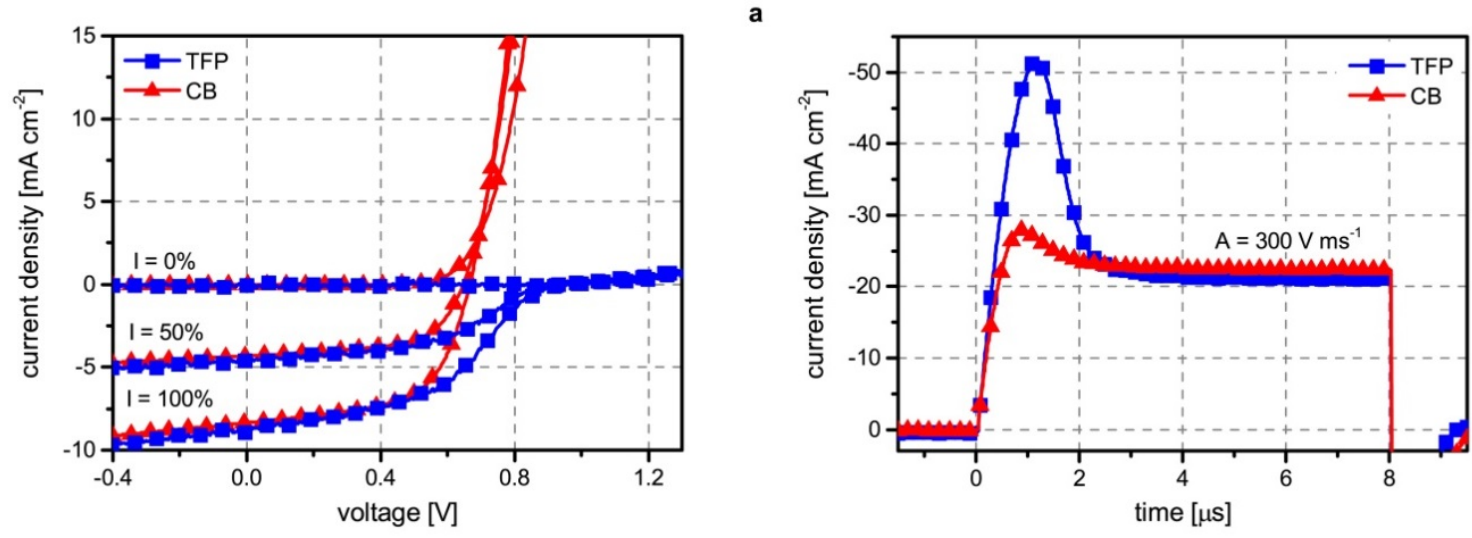

Figure 3. (a) Current-voltage characteristics using a blue LED at different light intensities. The Cy3-P was either spin coated from TFP (blue squares) or CB (red triangles). (b) PhotoCELIV measurements of the same cells in which the delay time was set to $0 \mu$ s and the volt$\operatorname{age} \operatorname{ramp} A$ was $300 \mathrm{~V} \mathrm{~ms}^{-1}$.

The device mobilities calculated from equation (1), with experimental parameters $A=300 \mathrm{~V}$ $\mathrm{ms}^{-1}$ and $t_{\text {delay }}=0 \mu \mathrm{s}$, are $(2.9 \pm 0.3) \cdot 10^{-5} \mathrm{~cm}^{2} \mathrm{~V}^{-1} \mathrm{~s}^{-1}$ and $(1.5 \pm 0.2) \cdot 10^{-5} \mathrm{~cm}^{2} \mathrm{~V}^{-1} \mathrm{~s}^{-1}$ for $\mathrm{CB}$ and TFP, respectively. For the calculation of mobility, the dielectric constant of fullerene $\varepsilon_{\mathrm{C} 60}=4.1$ was taken from literature ${ }^{47}$, while $\varepsilon_{\mathrm{Cy} 3-\mathrm{P}}=4.5$ was determined by impedance spectroscopy on an ITO/Cy3-P (70 nm)/Ag capacitor (supporting information, S2).

It is important to note that the RC-time constant $\tau_{\mathrm{RC}}$ of our circuit was measured to lie between $0.2 \mu \mathrm{s}$ and $0.25 \mu \mathrm{s}$ for both devices and thus imposes an upper limit for detecting mobility. Neukom et al. reported that the results obtained from analytical equation (1) are more accurate if the ratio between the CELIV peak time $t_{\max }$ and $\tau_{\mathrm{RC}}$ is high (typically $>10$ ) ${ }^{48}$. In the experiments presented here, this ratio is 4.0 and 5.2 for CB and TFP, respectively which is quite low and indicates that the calculated mobilities are probably underestimating the true value. Nevertheless, the two cells can be compared since the same experimental conditions were used. For smaller voltage ramps $t_{\max }$ increases and the $t_{\max } / \tau_{\mathrm{RC}}$ ratio gets higher. How- 
ever, within experimental error, the averaged mobilities obtained with a voltage sweep rate of $A=100 \mathrm{~V} \mathrm{~ms}^{-1}$ are the same as for $A=300 \mathrm{~V} \mathrm{~ms}^{-1}$.

The apparent mobility measured in both devices is several orders of magnitude lower than the electron mobility in pure $\mathrm{C}_{60}$. In field-effect transistors values up to $1 \mathrm{~cm}^{2} \mathrm{~V}^{-1} \mathrm{~s}^{-1}$ were measured $^{49,50}$. Space charge limited current analysis ${ }^{51}$ revealed a mobility of $5 \cdot 10^{-2} \mathrm{~cm}^{2} \mathrm{~V}^{-1} \mathrm{~s}^{-1}$ in $\mathrm{C}_{60}$ films of $1 \mu \mathrm{m}$ and for the fullerene derivative PCBM an electron mobility of $10^{-3} \mathrm{~cm}^{2} \mathrm{~V}^{-1}$ $\mathrm{s}^{-1}$ has been obtained by CELIV experiments ${ }^{52}$. For comparison, a peak related to such a high mobility would have a $t_{\max }$ of the same order of magnitude as $\tau_{\mathrm{RC}}$ and could therefore not be resolved in our experiment. Therefore we reason that the measured apparent mobility in our CELIV experiment relates to the positive charge carriers in Cy3-P. In order to further confirm this assignment, we varied the $\mathrm{C}_{60}$ layer thickness between $40 \mathrm{~nm}$ and $270 \mathrm{~nm}$ as proposed in another work $^{53}$. The calculated apparent mobilities obtained from equation (1) by attributing the CELIV peak to $\mathrm{C}_{60}$ or to Cy3-P, respectively, are presented in Table 1. For the calculated Cy3-P mobility $\mu_{\text {Cy3-P }}$ we see a trend to a constant value of approximately $4 \cdot 10^{-5} \mathrm{~cm}^{2} \mathrm{~V}^{-1} \mathrm{~s}^{-1}$ as the $\mathrm{C}_{60}$ layer thickness is increased. Assigning the CELIV peak to $\mathrm{C}_{60}$ leads to an unphysical increase of $\mu_{\mathrm{C} 60}$ by over one order of magnitude with thickening the $\mathrm{C}_{60}$ film. Therefore we conclude that the peak in the photo-CELIV transient relates to the hole mobility in Cy3-P. The same trend was observed for two cells with a $20 \mathrm{~nm}$ thick Cy3-P film coated from CB and using two $\mathrm{C}_{60}$ layer thicknesses of $40 \mathrm{~nm}$ or $216 \mathrm{~nm}$.

Table 1. Calculated apparent mobilities $\mu_{\text {Су3-P }}$ or $\mu_{\mathrm{C} 60}$ for different $\mathrm{C}_{60}$ layer thicknesses using equation (1) 


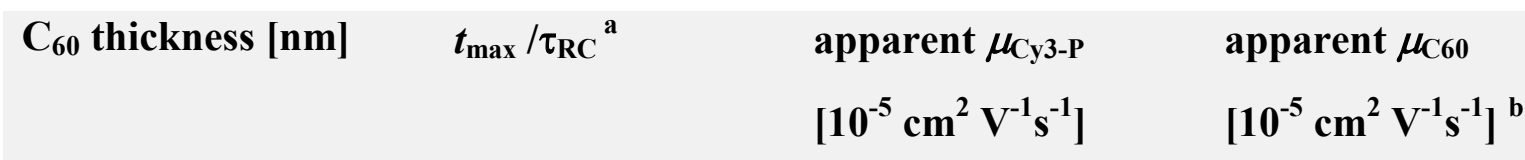

Cy3-P coated from TFP

$\begin{array}{llll}40 & 5.2 & 1.3 \pm 0.2 & 2.4 \pm 0.5 \\ 60 & 6.8 & 3.3 \pm 0.9 & 9.0 \pm 2.5 \\ 270 & 30 & 3.5 \pm 0.4 & 43 \pm 5\end{array}$

Cy3-P coated from CB

$\begin{array}{llll}40 & 4 & 2.9 \pm 0.3 & 5.2 \pm 0.6 \\ 216 & 24 & 4.4 \pm 1.4 & 43 \pm 14\end{array}$

${ }^{\mathrm{a}} \mathrm{As}$ an indicator for the reliability of the presented values the ratio $t_{\max } / \tau_{\mathrm{RC}}$ is also presented. ${ }^{\mathrm{b}} d_{\mathrm{Cy} 3-\mathrm{P}}$ and $\varepsilon_{\mathrm{Cy} 3-\mathrm{P}}$ are exchanged with $d_{\mathrm{C} 60}$ and $\varepsilon_{\mathrm{C} 60}$ in equation (1).

Varying the thickness of $\mathrm{C}_{60}$ from $40 \mathrm{~nm}$ to $270 \mathrm{~nm}$ also increases the $t_{\max } / \tau_{\mathrm{RC}}$ ratio considerably from 5.2 to 30 , respectively. Therefore the CELIV mobility extracted from devices with thick $\mathrm{C}_{60}$ films provides a more reliable reference value for the hole mobility in such cyanine films amounting to $3.5 \cdot 10^{-5} \mathrm{~cm}^{2} \mathrm{~V}^{-1} \mathrm{~s}^{-1}$ and $4.4 \cdot 10^{-5} \mathrm{~cm}^{2} \mathrm{~V}^{-1} \mathrm{~s}^{-1}$ for TFP and CB, respectively. For both TFP and CB coated devices, we have also increased the cyanine layer thickness by about a factor of two. For $38 \mathrm{~nm}$ thick CB films we now observe a clear S-shape and an increase in $V_{\text {oc }}$ and $J_{\text {sc }}$ (Figure $4 \mathrm{a}$ ). The number of extracted charge carriers as measured by photo-CELIV increases by a factor of 3.6 reflecting higher charge carrier generation and less efficient recombination. The calculated mobility $\mu_{\text {Су3 }-\mathrm{P}}=(5.2 \pm 0.2) \cdot 10^{-5} \mathrm{~cm}^{2} \mathrm{~V}^{-1} \mathrm{~s}^{-1}$ is higher than for devices using $20 \mathrm{~nm}$ thick cyanine films. However it is very similar to above reference value measured in devices with very thick $\mathrm{C}_{60}$ layers. In the case of $38 \mathrm{~nm}$ thick cyanine films coated from TFP, the $I-V$ characteristic worsens considerably showing a fill factor of only $23 \%$ (data not shown). Interestingly, the number of charge carriers extracted by photo-CELIV remains constant, despite the fact that the short circuit current has increased by $50 \%$ with re- 
spect to devices with $20 \mathrm{~nm}$ thick cyanine films. We also note that the capacitive current in Figure $4 \mathrm{~b}$ observed for $20 \mathrm{~nm}$ is only slightly higher than for the $38 \mathrm{~nm}$ thick films and does not reflect the increase in geometrical capacitance. This is due to the high roughness of the cyanine films coated form $\mathrm{CB}$ which increases the capacitance of the thick films.
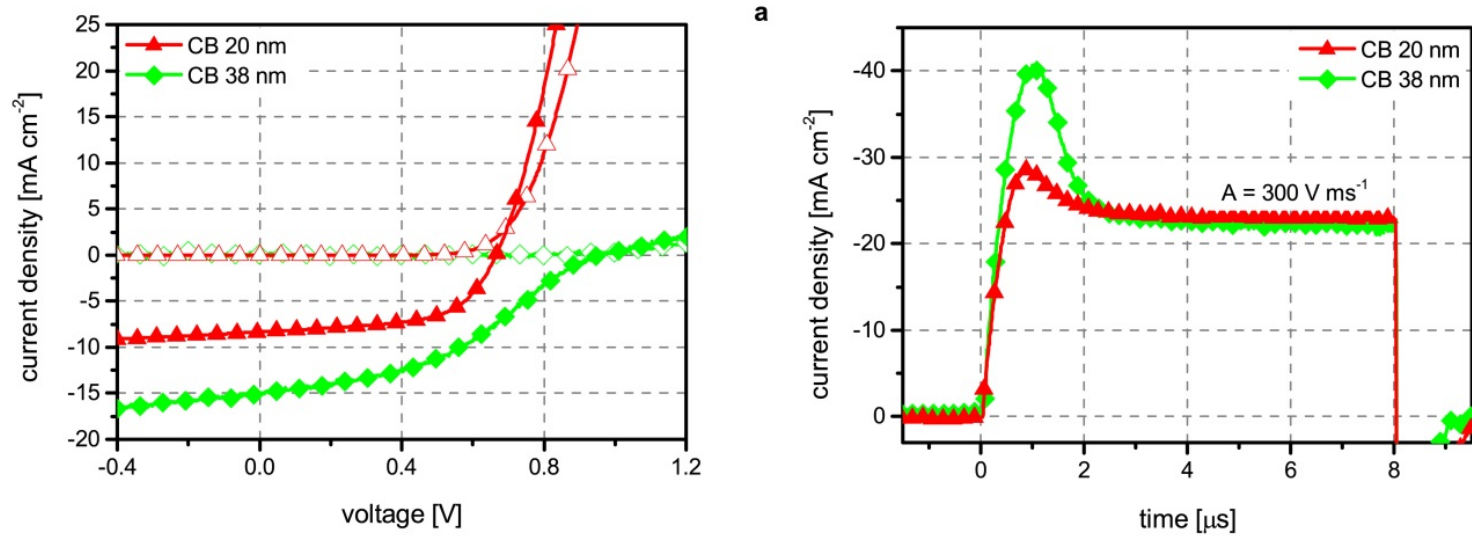

Figure 4. Current-voltage characteristics using a blue LED with $0 \%$ (open symbols) and $100 \%$ (full symbols) light intensity of cells with different Cy3-P thicknesses coated from CB (a). Photo-CELIV measurements of the same cells are shown in (b).

While the CELIV measurements have not revealed a major difference of the apparent mobility between devices fabricated using TFP or $\mathrm{CB}$, there is an obvious difference in the number of charge carriers extracted in films with a cyanine thickness of $20 \mathrm{~nm}$. This contrasts with the comparable charge carrier generation under short circuit conditions as reflected by almost identical IPCE spectra for both coating solvents. By integrating over the CELIV peak, the charge density in the cyanine layer amounts to $1.1 \cdot 10^{17} \mathrm{~cm}^{-3}$ and $1.8 \cdot 10^{16} \mathrm{~cm}^{-3}$ for the TFP and CB device, respectively (Figure 3b). Another fundamental difference between the two devices comes from photo-CELIV measurements with delay time $t_{\text {delay }}$ varied between 1 and $200 \mu \mathrm{s}$ (Figure 5a). During the light pulse and the delay time, the voltage is adjusted to $V_{\text {oc }}$ and therefore charges are not extracted. The decrease in the amount of extracted charge therefore can 
be ascribed to the recombination of positive and negative charge carriers present in the device just after the light pulse. After a delay time of $200 \mu$ s only $20 \%$ of the charge carriers have recombined in devices with a $20 \mathrm{~nm}$ thick Cy3-P layer deposited from TFP, compared to $89 \%$ in devices where the cyanine film of equal thickness was deposited from CB. Due to the small overshoot in the latter case, the determination of the number of extracted charge carriers was difficult for higher delay times. Increasing the layer thickness of the latter Cy3-P film increased the fraction of recombined carriers to $95 \%$. Figure $5 \mathrm{~b}$ displays the integrated peak area from Figure $5 \mathrm{a}$ which was normalized to the charge density $n_{0}$ measured at delay time zero and obtained from Figure $3 \mathrm{~b}$ and $4 \mathrm{~b}$, assuming a homogeneous charge distribution over the cyanine layer. In the following, we define the lifetime $\tau$ of photogenerated carriers as the time at which the charge density has decreased by $1 / 2$ of its initial value. Most strikingly, the carrier lifetime in TFP coated devices of $\tau_{\text {TFP }}$ is much longer than $200 \mu \mathrm{s}$. It is at least two orders of magnitude longer than in $\mathrm{CB}$ coated devices where $\tau_{\mathrm{CB}}$ ranges from $1 \mu$ s to $3.5 \mu$ s for devices with cyanine layer thicknesses of $20 \mathrm{~nm}$ and $38 \mathrm{~nm}$, respectively. This is in sharp contrast to the apparent mobility related to $t_{\max }$ in the photo-CELIV measurement, which is of the same order of magnitude in films coated from the two solvents, respectively. In the case of devices employing $38 \mathrm{~nm}$ thick cyanine films coated from TFP, the recombination kinetics exhibit a faster recombination rate than for $20 \mathrm{~nm}$ thick films. Contrary to devices prepared from $\mathrm{CB}$, however, still $40 \%$ of the initial charge carriers can be extracted after a $200 \mu$ s delay time (supporting information, S3). Based on above observations, the huge differences observed in the photogenerated carrier lifetimes in devices coated from CB and TFP, respectively, cannot be explained by the morphological differences between the two films. Even for thick continuous cyanine films coated from $\mathrm{CB}$ we do observe much faster recombination kinetics as compared to films coated from TFP. 

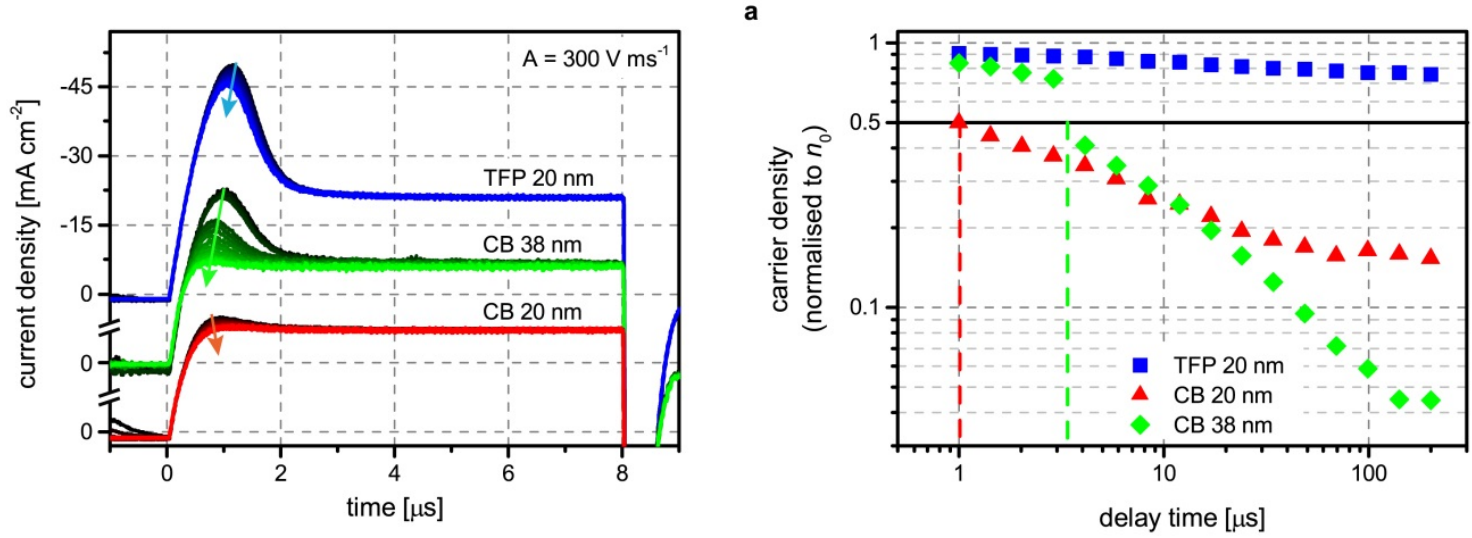

b

Figure 5. (a) Photo-CELIV measurements with logarithmically varied delay times between 1 and $200 \mu$ s. The Cy3P layers were spin coated from TFP (blue) or CB (red, green) and had a thickness of 20 (blue, red) and $40 \mathrm{~nm}$ (green), respectively. The arrows indicate the evolution of $t_{\max }$ for increasing $t_{\text {delay. }}$ (b) Charge carrier density obtained from integrating the peak area of the photo-CELIV transients in (a) as a function of delay time. Half lifetimes of charge carriers are indicated by dashed vertical lines.

Capacitance-voltage $(C-V)$ characteristics of the cells with various Cy3-P layer thicknesses are presented in Figure 6. In order not to be limited by the transit times of electrons and holes through the device, a frequency of $10 \mathrm{kHz}$ was chosen. The cells comprising $20 \mathrm{~nm}$ thick donor layers reflect the striking dependence on the solvents used for coating the cyanine film. In the TPF case, the highest capacitance increase around $V_{\mathrm{oc}}$ is measured when $20 \mathrm{~nm}$ thin films are used. The maximum capacitance decreases considerably when the thickness of the cyanine layer is increased to $38 \mathrm{~nm}$, indicating that the determining factor is related to the geometrical capacitance of the cyanine film. In the case of $\mathrm{CB}$, the maximum capacitance of the device with the $20 \mathrm{~nm}$ thick donor layer is much smaller and breaks down quickly above $V_{\text {oc }}$. At a cyanine film thickness of $38 \mathrm{~nm}$ the capacitance keeps increasing steadily with increasing voltage and reaches its maximum at about twice the voltage observed in the case of $20 \mathrm{~nm}$ 
thick cyanine films coated from $\mathrm{CB}$. Again the $C-V$ characteristics reveal a striking difference related to the coating solvent used to deposit the cyanine layer.

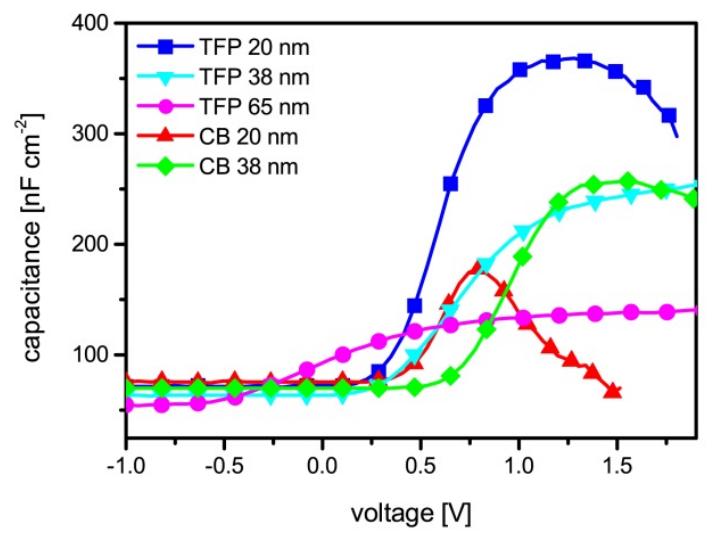

Figure 6. Capacitance-voltage characteristics measured at a frequency of $10 \mathrm{kHz}$ of cells with different Cy3-P layer thicknesses, coated either from TFP or CB.

\section{DISCUSSION}

Many reasons leading to an S-shaped $I-V$ characteristic in bilayer solar cell devices have been identified in the literature and can be divided into two main categories. First, there are effects originating from the active bulk semiconductor such as mobility imbalance between donor and acceptor materials of equal layer thicknesses ${ }^{54,55}$. Then there are electrode or interface problems arising from poor injection due to an insulating tunneling barrier or a non-matching work function ${ }^{56-58}$. Other works have correlated the presence of traps at the metal cathode with the appearance of a kink in the $I-V$ characteristic ${ }^{59,60}$.

In our study we observed a marked difference in the $I-V$ characteristics of devices with cyanine donor layers coated from two different solvents. For $20 \mathrm{~nm}$ thick Cy3-P layers a strong kink appears only when polar TFP is used as a coating solvent. In the case of less polar CB, Sshape behavior can only be observed for thicker cyanine layers. The latter feature can be ex- 
plained by invoking the large charge carrier mobility imbalance between the cyanine donor and the fullerene acceptor. From photo-CELIV experiments we obtain typical mobility values of $4 \cdot 10^{-5} \mathrm{~cm}^{2} \mathrm{~V}^{-1} \mathrm{~s}^{-1}$ which we have ascribed to the mobility of holes in the previous section. Thus hole mobility is about three orders of magnitude lower than the one of electrons in $\mathrm{C}_{60}$ as obtained from space charge limited current analysis ${ }^{51}$. According to an experimental and theoretical study on bilayer solar cell devices, S-shaped behaviour appears already when electron and hole mobilities differ by a factor 100 , given that the respective layer thicknesses are comparable ${ }^{54}$.

It is more difficult to understand the significant difference we observe for the $I-V$ characteristics of devices using regular layer sequence and comprising $20 \mathrm{~nm}$ thick cyanine films coated from different solvents. Although the choice of solvent may influence structural properties of the spin coated films, a drastic variation of hole mobility can be ruled out from the measured CELIV device mobility. As presented in Table 1, devices with thick $\mathrm{C}_{60}$ layers and hence high $t_{\max } / \tau_{\mathrm{RC}}$ ratios present reliable positive charge carrier mobilities of roughly $4 \cdot 10^{-5} \mathrm{~cm}^{2} \mathrm{~V}^{-1} \mathrm{~s}^{-1}$ for cyanine films deposited from TFP or CB. The hypothesis that TFP leads to films with inferior charge transport properties can also be precluded by the fact that devices coated from TFP but using an inverted layer sequence, i.e. $\mathrm{ITO} / \mathrm{TiO}_{\mathrm{x}} / \mathrm{C}_{60} / \mathrm{Cy} 3-\mathrm{P} / \mathrm{MoO}_{3} / \mathrm{Ag}$, presents an excellent $I-V$ characteristic without S-kink and with FF reaching $69 \%{ }^{61}$. The CELIV peak of inverted devices was observed to be very small and the calculated mobility was similar to the one of regular devices using $\mathrm{CB}$ as coating solvent (supporting information, S4). Therefore, deterioration of bulk electronic properties of the Cy3-P film coated from TFP can be eliminated as being the reason for inferior device performance. The cause of S-shaped characteristic using $20 \mathrm{~nm}$ thick cyanine films coated from TFP may therefore come from specific interface formation. The very long ( $>200 \mu$ s) effective lifetimes obtained from the photo-CELIV transients at different delay times indicates that charge carriers must be blocked or trapped close 
to this interface. Both interfaces, the one between $\mathrm{MoO}_{3}$ and $\mathrm{Cy} 3-\mathrm{P}$ or the one between $\mathrm{Cy} 3-\mathrm{P}$ and $\mathrm{C}_{60}$ can be invoked.

In the latter case, diffusion of $\mathrm{C}_{60}$ into the cyanine layer during vapor deposition of the fullerene could lead to isolated fullerene clusters giving rise to trapped photogenerated electrons. Such phenomena have been observed for polymer films ${ }^{26,62-64}$ and require certain film porosity, which we were not able to detect on the scale accessible by surface probe microscopy. The rms roughness of $0.63 \mathrm{~nm}$ was measured for films coated from TFP (supporting information, S5). More decisively, electron trapping within the cyanine layer would lead to strong recombination and reduce the photo-generation of free charge carriers. On the contrary, we observe identical $J_{s c}$ and IPCE for both TFP and CB coating solvents, strongly speaking against $\mathrm{C}_{60}$ cluster formation at the cyanine-fullerene interface. Further evidence comes from the capacitance-voltage characteristics (Figure 6). Looking at the devices with $20 \mathrm{~nm}$ thick Cy3-P films, the maximum capacitance achieved when using TFP as a coating solvent is five times higher than in the case of $\mathrm{CB}$. The voltage increases around $V_{\mathrm{oc}}$, which is the critical voltage above which charge carriers start to be injected from cathode and anode. An enhancement in the capacitance can come from dissymmetric charge injection from cathode and anode ${ }^{65}$. Given the fact that the cathode interface is identical in devices coated from TFP and CB, we conclude that it is the anode interface that retains positive charge carriers in the case of TFP. For the 38 nm thick films the low mobility of holes limits transport of positive charge carriers to the organic heterointerface at voltages close to $V_{\mathrm{oc}}$, corroborating with the mobility limitation for the extraction of photogenerated holes in $38 \mathrm{~nm}$ thick cyanine layer devices with low fill factor and high $V_{\mathrm{oc}}$. Only at even higher voltages, holes efficiently recombine with electrons leading to the breakdown of the capacitance. For both the $20 \mathrm{~nm}$ and $38 \mathrm{~nm}$ thick films, respectively, breakdown occurs at much lower voltages when the devices are coated from $\mathrm{CB}$ compared to TFP films of the respective thickness. We have attributed this observation to the 
fact that holes are retained in the vicinity of the anode interface when films are prepared from TFP. However, we cannot exclude enhanced recombination in the case of films prepared from CB due to morphological issues.

For above reasons we therefore favor the hypothesis that the coating solvent affects interface formation at the $\mathrm{MoO}_{3}$-cyanine interface. Specific solvent substrate interaction is evidenced by the much better wetting of freshly vapor deposited $\mathrm{MoO}_{3}$ layers by TFP in comparison to $\mathrm{CB}$, where complete dewetting of cyanine layers with nominal thicknesses $<5 \mathrm{~nm}$ occurs (supporting information, S6), which is not observed when using TFP solutions. The $\mathrm{MoO}_{3}$ surface is well known as catalytically active surface ${ }^{66-68}$ and provides acidic as well as basic surface sites. Such sites could very well interact with the fluorinated alcohol, e.g. via hydrogen bonding. Formation of a solvent surface layer would also give rise to a significant surface potential shift, if surface adsorbed dipoles do not compensate each other. Kelvin probe force microscopy was performed on ITO/ $\mathrm{MoO}_{3}$ substrates onto which pure solvent was coated, but did not reveal any significant potential shift. A series of devices where pure TFP was first spin coated on $\mathrm{MoO}_{3}$ before completing the cell with Cy3-P (from $\mathrm{CB}$ ) $/ \mathrm{C}_{60} / \mathrm{Alq}_{3} / \mathrm{Ag}$ structure was fabricated to test a potential reaction between the $\mathrm{MoO}_{3}$ and pure TFP. The performances of these devices were similar to the ones from the control cells. Thus, a TFP induced barrier at the $\mathrm{MoO}_{3}$ surface is excluded as a reason for charge accumulation at the anode.

It has been observed that spin-coating of polyelectrolytes at the electrode interface can significantly improve solar cell device performance due to dipole formation by ionic displacement $^{69}$. Vertical ionic distribution may also occur when spin-coating cyanine salts. Cyanine counteranions $\left(\mathrm{PF}_{6}{ }^{-}\right)$in TFP are completely decoupled from the cationic chromophore while there is strong coupling in the case of $\mathrm{CB}^{70}$. Ionic distribution gradients are therefore more likely to build in TFP coated films. Kelvin probe force microscopy was also performed on substrates with the structure ITO/ $\mathrm{MoO}_{3} / \mathrm{Cy} 3-\mathrm{P}(5 \mathrm{~nm}, 20 \mathrm{~nm})$ coated from both solvents. The 
surface potential showed no difference between the solvents for the same film thicknesses and thus no dipole was detected. This also indicates that using TFP solutions on $\mathrm{MoO}_{3}$ coated ITO/glass substrates do not greatly affect the effective work function of the oxide anode. Indeed, the open circuit voltage is even slightly increased when fabricating devices with TFP instead of CB.

Even though a simple injection barrier such as a tunneling contact may explain the appearance of an S-kink in the $I-V$ characteristic, it would not be sufficient to describe the extremely long effective hole lifetime as measured for $20 \mathrm{~nm}$ thick cyanine films from TFP (Figure 5). A simple tunneling junction would prevent carriers from entering the anode contact, but would not impede recombination between electrons and holes at the organic heterojunction, which occurs within a few microseconds as we have measured for CB coated devices. Charge carriers therefore have to be trapped close to the anode interface, in order to account for the effective lifetimes measured for TFP coated cyanine films. Such trapping could be due to specific aggregation of cyanine molecules at the $\mathrm{MoO}_{3}$ surface decreasing the HOMO level with respect to the amorphous phase of the film. For cyanine dyes with high absorption coefficients, aggregation phenomena can easily be followed by looking at specific shoulders in the absorption spectrum. No difference in the spectral shape could be seen between ultra-thin films of nominally $1.25 \mathrm{~nm}$ being coated from either TFP or CB (supporting information, S1). Therefore the hypothesis of specific cyanine aggregation leading to charge trapping is not likely either.

It has been demonstrated that traces of solvents may still be present in organic solar cell devices, even though they had undergone prolonged heat treatment ${ }^{71}$. In a former work, residual TFP coating solvent was found in a heptamethine cyanine film after drying the films in vacuum for several hours. Up to 3\% solvent molecules per dye molecules were measured in the dried films using GC-MS ${ }^{72}$. To study possible TFP retention in our system, the morphology of 
ITO/ $\mathrm{MoO}_{3} / \mathrm{Cy} 3-\mathrm{P}$ devices was studied by surface probe microscopy (SPM) after drying the coated films at room temperature for $2.5 \mathrm{~h}$ either in the glove box or in the vacuum chamber at $4.6 \cdot 10^{-6}$ mbar (supporting information, S5). A clear difference in the surface roughness was observed. While the film that was not exposed to vacuum showed only few bumps and holes, the surface of the vacuum dried film was covered with volcano-like structures with a typical width of $100 \mathrm{~nm}$ to $200 \mathrm{~nm}$ providing from the effusion of solvent. XPS measurements were carried out to confirm the presence of TFP and to uMRavel the location of trapped solvent. For this purpose, a series of Cy3-P films on $\mathrm{MoO}_{3}$ with different thicknesses were made. The films were introduced to the high vacuum chamber and were kept in the vacuum for the duration of about 1 hour during the measurement. For the $40 \mathrm{~nm}$ thick Cy3-P film the spectrum shows peaks for F, N, C and P which can all be attributed to the dye film itself (supporting information S7). The thinner the Cy3-P film, the larger the oxygen and Mo signal originating from the $\mathrm{MoO}_{3}$ substrate. As the $\mathrm{P}$ signal can only originate from the cyanine counterion $\mathrm{PF}_{6}^{-}$ it was used to estimate its concentration. The F signal is composed of two contributions coming from the counterion and the solvent TFP. We observe an increase of the F : P ratio when the Cy3-P film thickness is decreased. For the $40 \mathrm{~nm}$ thick film, the $\mathrm{F}: \mathrm{P}$ ratio is equal to the one in the counterion alone whereas in the $2.5 \mathrm{~nm}$ thick film, 3 solvent molecules per 4 counterions are present, which clearly supports the hypothesis of a solvent accumulation layer at the oxide anode.

We speculate that the residual TFP forms a solvent rich layer at the $\mathrm{MoO}_{3}$ interface which partly solubilizes Cy3-P molecules thereby considerably reducing $\pi$-orbital stacking. This would drastically decrease electron transport efficiency which is further reduced by the high dielectric constant of the solvent $\left(\varepsilon_{\mathrm{TFP}}=20\right)^{73}$ lowering the local electric field close to the anode interface. In contrast to this, less polar and aromatic CB shows solution dewetting on $\mathrm{MoO}_{3}$ surfaces and therefore will not build up a solvent rich interface layer. This corroborates 
the fact that charge trapping at the anode interface could not be observed using CB as coating solvent. The bilayer cell consisting of a $20 \mathrm{~nm}$ thick cyanine and a $40 \mathrm{~nm}$ thick $\mathrm{C}_{60}$ film was modelled using a drift-diffusion model coupled to the multilayer optical simulation based on the transfer matrix formalism implemented in $\operatorname{SETFOS}^{45}$. To simulate charge generation at the $\mathrm{Cy} 3-\mathrm{P} / \mathrm{C}_{60}$ interface, a $1 \mathrm{~nm}$ thick generation layer was inserted between the two active layers. The optical charge generation rate was set to zero everywhere in the device except for the generation layer. To mimic the solvent barrier in the TFP cell, the first nanometer of Cy3$\mathrm{P}$ at the $\mathrm{MoO}_{3}$ interface was replaced by a $1 \mathrm{~nm}$ thin layer with a dielectric constant of pure TFP, smaller mobility and a lower density of states compared to Cy3-P keeping the same frontier orbital energy levels. The energy level diagram for the TFP cell is shown in the inset of Figure 7a. Morphology control in $20 \mathrm{~nm}$ thick CB films is difficult and may result in noncontinuous films with lower $V_{\mathrm{oc}}$. To facilitate modeling we have taken $I-V$ data from a continuous film deposited from $\mathrm{CB}$ with comparable $V_{o c}$ to the corresponding film coated from TFP. We assumed that there is no injection limitation from the electrodes which are $\mathrm{MoO}_{3}$ on the anode side and $\mathrm{Ag} / \mathrm{Alq}_{3}$ on the cathode side. Since we used the thermionic injection model according to Scott et $a l^{74}$ we had to introduce a small barrier which we chose to be $0.1 \mathrm{~V}$, avoiding contact limitation of the current and respecting barrier limitation proper to the implemented model. In Figure $7 \mathrm{a}$ the simulated and measured $I-V$ characteristics for TFP and CB are presented. Qualitatively, the S-shape observed in the experiments was reproduced using this model. Similar modeling studies were carried out using a sigmoid drop of the mobility close to an electrode contact, also revealing the appearance of an S-shaped $I-V$ curve. The sketch in Figure $7 \mathrm{~b}$ summarizes the difference in the solar cells at flat band condition coated from TFP and CB, respectively. In CB devices, charge carriers can diffuse freely in the donor and the acceptor layer. This is also true for devices coated from TFP except for one fraction of holes that are trapped at the $\mathrm{MoO}_{3}$-cyanine interface due to residual, accumulated solvent. Thus, holes can hardly reach the heterojunction to recombine with an electron. For devices 
with $20 \mathrm{~nm}$ thick cyanine layers recombination between electrons and holes at open circuit condition is so efficient that only few free charge carriers remain to be extracted by photoCELIV. The very slow recombination kinetic in $20 \mathrm{~nm}$ thick TFP films therefore principally relates to trapped charge carriers at the $\mathrm{MoO}_{3}$ interface (Figure 5). For thicker cyanine layers, however, the number of free charge carriers should increase with respect to the number of trapped ones. This can indeed be observed by an increase of the proportion of extracted charge carriers following fast recombination kinetics (supporting information, S3).

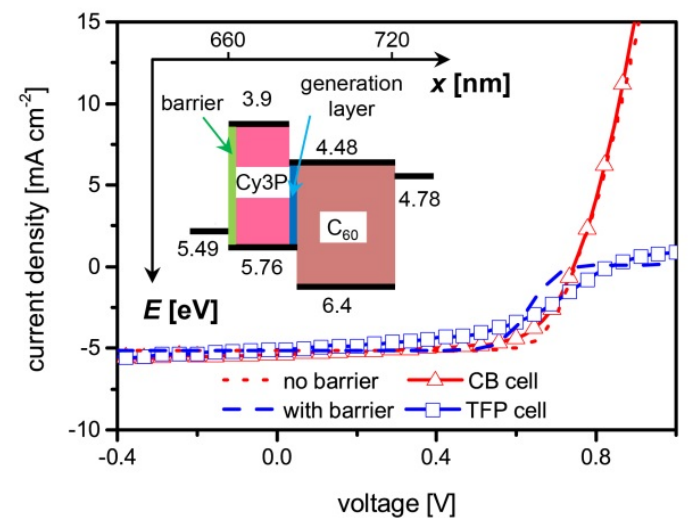

a
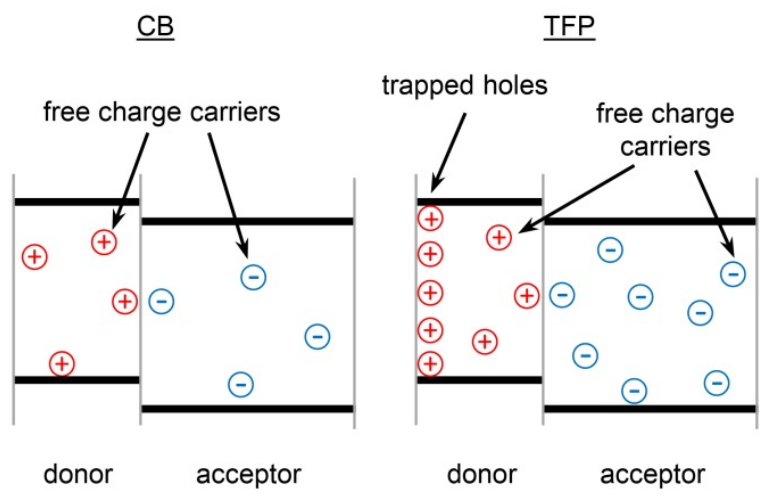

Figure 7. (a) Simulation of the current-voltage characteristics of a bilayer cell with (blue dashed) and without barrier (red dotted) at the $\mathrm{MoO}_{3} / \mathrm{Cy} 3 \mathrm{P}$ interface and experimentally measured curves of cells coated from CB (red triangles) and TFP (blue squares). The inset shows the energy level situation to model the dashed blue curve, for the dotted red one the barrier was omitted. (b) Sketch of hole and electron densities in the device at $V_{\mathrm{oc}}$ for the TFP and the CB situation. For TFP most of the holes are trapped at the interface because of the residual solvent, whereas charges move freely in the CB situation.

\section{CONCLUSIONS}

Fabrication of bilayer heterojunction solar cells with regular layer sequence and incorporating a cyanine dye donor and $\mathrm{C}_{60}$ acceptor stands out by a marked solvent sensitivity. While devic- 
es coated from CB show current-voltage curves with high fill factors, a marked S-kink is observed when TFP is used as coating solvent for the cyanine layer. By using capacitancevoltage measurements and photo-CELIV experiments with varying delay time for extraction of charge carriers in these bilayer devices, we were able to reveal the existence of trapped positive charge carriers at the anode interface. These trapped charge carriers are characterized by lifetimes $>200 \mu$ s at open circuit conditions and can be clearly distinguished from untrapped charge carriers in the cyanine film. We found that the trapping mechanism originates from a solvent rich layer retained at the $\mathrm{MoO}_{3}$ anode interface which has the effect of reducing charge carrier mobility by partially solubilizing the cyanine film. While this phenomenon appears with highly polar fluorinated alcohol (TFP), it is not observed with chlorobenzene being aromatic and less polar. Our study emphasizes the difficulties peculiar to solution processing and pinpoints the importance of solvent-substrate surface affinity. It also provides a starting point for developing specific surface treatments that may avoid solvent retention and therefore improve the fill factor of organic solar cell devices and their performance.

\section{ASSOCIATED CONTENT}

\section{Supporting Information}

Figures of absorption spectra of glass $/ \mathrm{MoO}_{3} / \mathrm{Cy} 3-\mathrm{P}$ samples, the capacitance of a cyanine film as a function of frequency, photo-CELIV measurements of $\mathrm{Cy} 3-\mathrm{P} / \mathrm{C}_{60}$ solar cells with a thick cyanine layer, photo-CELIV measurement of $\mathrm{Cy} 3-\mathrm{P} / \mathrm{C}_{60}$ solar cells with inverted layer sequence, SPM images of Cy3-P films under different drying conditions and dewetting of $5 \mathrm{~nm}$ thick Cy3-P films on $\mathrm{MoO}_{3}$, XPS analysis of ITO/MoO3/Cy3-P samples. This material is available free of charge via the Internet at http://pubs.acs.org. 


\section{AUTHOR INFORMATION}

\section{Corresponding author}

*E-mail: frank.nueesch@empa.ch. Phone: +41 58 7654740. Fax: +41 587654012

\section{Notes}

The authors declare no competing financial interest.

\section{ACKNOWLEDGEMENT}

Authors Sandra Jenatsch, Roland Hany, Beat Ruhstaller and Frank Nüesch would like to acknowledge financial support by the Swiss National Science Foundation (project No.200021_144120/1). We thank Jakob Heier and Roland Steim for helpful discussions. We gratefully acknowledge Alessandra Beni and Patrik Schmutz for Kelvin probe force microscopy (AFM-KPFM) and Jean-Nicolas Tisserant for surface probe microscopy (SPM).

\section{REFERENCES}

(1) Machui, F.; Brabec, C. J. Solubility, Miscibility, and the Impact on Solid-State Morphology; in Semiconducting Polymer Composites: Principles, Morphologies, Properties and Applications; John Wiley \& Sons, Inc., 2013.

(2) Nilsson, S.; Bernasik, A.; Budkowski, A.; Moons, E. Morphology and Phase Segregation of Spin-Casted Films of Polyfluorene/PCBM Blends. Macromolecules 2007, 40 (23), 8291-8301. 
(3) Ruderer, M. A.; Guo, S.; Meier, R.; Chiang, H. Y.; Korstgens, V.; Wiedersich, J.; Perlich, J.; Roth, S. V.; Muller-Buschbaum, P. Solvent-Induced Morphology in PolymerBased Systems for Organic Photovoltaics. Adv. Funct. Mater. 2011, 21 (17), 3382-3391.

(4) Moule, A. J.; Meerholz, K. Controlling Morphology in Polymer-Fullerene Mixtures. Adv. Mater. 2008, 20 (2), 240-245.

(5) Aich, B. R.; Lu, J. P.; Beaupre, S.; Leclerc, M.; Tao, Y. Control of the Active Layer Nanomorphology by Using Co-Additives Towards High-Performance Bulk Heterojunction Solar Cells. Org. Electron. 2012, 13 (9), 1736-1741.

(6) Chu, T.-Y.; Lu, J.; Beaupre, S.; Zhang, Y.; Pouliot, J.-R.; Wakim, S.; Zhou, J.; Leclerc, M.; Li, Z.; Ding, J.; Tao, Y. Bulk Heterojunction Solar Cells Using Thieno 3,4-C Pyrrole-4,6-Dione and Dithieno 3,2-B:2 ',3 '-D Silole Copolymer with a Power Conversion Efficiency of 7.3\%. J. Am. Chem. Soc. 2011, 133 (12), 4250-4253.

(7) Lee, J. K.; Ma, W. L.; Brabec, C. J.; Yuen, J.; Moon, J. S.; Kim, J. Y.; Lee, K.; Bazan, G. C.; Heeger, A. J. Processing Additives for Improved Efficiency from Bulk Heterojunction Solar Cells. J. Am. Chem. Soc. 2008, 130 (11), 3619-3623.

(8) Brabec, C. J.; Cravino, A.; Meissner, D.; Sariciftci, N. S.; Fromherz, T.; Rispens, M. T.; Sanchez, L.; Hummelen, J. C. Origin of the Open Circuit Voltage of Plastic Solar Cells. Adv. Funct. Mater. 2001, 11 (5), 374-380.

(9) Fortunato, E.; Ginley, D.; Hosono, H.; Paine, D. C. Transparent Conducting Oxides for Photovoltaics. MRS Bulletin 2007, 32 (3), 242-247.

(10) Mihailetchi, V. D.; Blom, P. W. M.; Hummelen, J. C.; Rispens, M. T. Cathode Dependence of the Open-Circuit Voltage of Polymer : Fullerene Bulk Heterojunction Solar Cells. J. Appl. Phys. 2003, 94 (10), 6849-6854.

(11) He, Z.; Zhong, C.; Su, S.; Xu, M.; Wu, H.; Cao, Y. Enhanced Power-Conversion Efficiency in Polymer Solar Cells Using an Inverted Device Structure. Nature Photon. 2012, $6(9), 591-595$. 
(12) Minemawari, H.; Yamada, T.; Matsui, H.; Tsutsumi, J. y.; Haas, S.; Chiba, R.; Kumai, R.; Hasegawa, T. Inkjet Printing of Single-Crystal Films. Nature 2011, 475 (7356), 364-367.

(13) Chen, Z. H.; Muller, P.; Swager, T. M. Syntheses of Soluble, pi-Stacking Tetracene Derivatives. Org. Lett. 2006, 8 (2), 273-276.

(14) Mativetsky, J. M.; Kastler, M.; Savage, R. C.; Gentilini, D.; Palma, M.; Pisula, W.; Mullen, K.; Samori, P. Self-Assembly of a Donor-Acceptor Dyad across Multiple Length Scales: Functional Architectures for Organic Electronics. Adv. Funct. Mater. 2009, 19 (15), 2486-2494.

(15) Liu, S. H.; Wang, W. C. M.; Mannsfeld, S. C. B.; Locklin, J.; Erk, P.; Gomez, M.; Richter, F.; Bao, Z. N. Solution-Assisted Assembly of Organic Semiconducting Single Crystals on Surfaces with Patterned Wettability. Langmuir 2007, 23 (14), 7428-7432.

(16) Brück, S.; Krause, C.; Turrisi, R.; Beverina, L.; Wilken, S.; Saak, W.; Lützen, A.; Borchert, H.; Schiek, M.; Parisi, J. Structure-Property Relationship of Anilino-Squaraines in Organic Solar Cells. Phys. Chem. Chem. Phys. 2014, 16, 1067-1077.

(17) Zimmerman, J. D.; Lassiter, B. E.; Xiao, X.; Sun, K.; Dolocan, A.; Gearba, R.; Vanden Bout, D. A.; Stevenson, K. J.; Wickramasinghe, P.; Thompson, M. E.; Forrest, S. R. Control of Interface Order by Inverse Quasi-Epitaxial Growth of Squaraine/Fullerene Thin Film Photovoltaics. ACS Nano 2013, 7 (10), 9268-9275.

(18) Hany, R.; Fan, B.; de Castro, F. A.; Heier, J.; Kylberg, W.; Nuesch, F. Strategies to Improve Cyanine Dye Multi Layer Organic Solar Cells. Progr. Photovoltaics 2011, 19 (7), $851-857$

(19) Tisserant, J.-N.; Wicht, G.; Goebel, O. F.; Bocek, E.; Bona, G.-L.; Geiger, T.; Hany, R.; Mezzenga, R.; Partel, S.; Schmid, P.; Schweizer, W. B.; Heier, J. Growth and Alignment of Thin Film Organic Single Crystals from Dewetting Patterns. ACS Nano 2013, 7 (6), 55065513. 
(20) Silvestri, F.; Irwin, M. D.; Beverina, L.; Facchetti, A.; Pagani, G. A.; Marks, T. J. Efficient Squaraine-Based Solution Processable Bulk-Heterojunction Solar Cells. J. Am. Chem. Soc. 2008, 130 (52), 17640-17641.

(21) Sun, Y.; Welch, G. C.; Leong, W. L.; Takacs, C. J.; Bazan, G. C.; Heeger, A. J. Solution-Processed Small-Molecule Solar Cells with 6.7\% Efficiency. Nature Mater. 2012, $11(1), 44-48$.

(22) Walker, B.; Tomayo, A. B.; Dang, X.-D.; Zalar, P.; Seo, J. H.; Garcia, A.; Tantiwiwat, M.; Nguyen, T.-Q. Nanoscale Phase Separation and High Photovoltaic Efficiency in SolutionProcessed, Small-Molecule Bulk Heterojunction Solar Cells. Adv. Funct.Mater. 2009, 19 (19), 3063-3069.

(23) Van Dijken, J. G.; Fleischauer, M. D.; Brett, M. J. Solvent Effects on Znpc Thin Films and Their Role in Fabrication of Nanostructured Organic Solar Cells. Org. Electron. 2011, 12 (12), 2111-2119.

(24) Liu, Y.; Chen, C.-C.; Hong, Z.; Gao, J.; Michael Yang, Y.; Zhou, H.; Dou, L.; Li, G.; Yang, Y. Solution-Processed Small-Molecule Solar Cells: Breaking the 10\% Power Conversion Efficiency. Sci. Reports 2013, 3, 3356-3356.

(25) Ayzner, A. L.; Tassone, C. J.; Tolbert, S. H.; Schwartz, B. J. Reappraising the Need for Bulk Heterojunctions in Polymer-Fullerene Photovoltaics: The Role of Carrier Transport in All-Solution-Processed P3HT/PCBM Bilayer Solar Cells. J. Phys. Chem. C 2009, 113 (46), 20050-20060.

(26) Chen, T.; Aljada, M.; Shaw, P. E.; Lee, K. H.; Cavaye, H.; Balfour, M. N.; Borthwick, R. J.; James, M.; Burn, P. L.; Gentle, I. R.; Meredith, P. Controlling Hierarchy in SolutionProcessed Polymer Solar Cells Based on Crosslinked P3HT. Adv. Energ. Mater. 2013, 3 (1), $105-112$ 
(27) Chen, T. L.; Chen, J. J.-A.; Catane, L.; Ma, B. Fully Solution Processed P-I-N Organic

Solar Cells with an Industrial Pigment - Quinacridone. Org. Electron. 2011, 12 (7), 11261131.

(28) Lassiter, B. E.; Zimmerman, J. D.; Panda, A.; Xiao, X.; Forrest, S. R. Tandem Organic Photovoltaics Using Both Solution and Vacuum Deposited Small Molecules. Appl. Phys. Lett. 2012, $101(6), 063303$.

(29) Ghani, F.; Bochukov, I.; Fostiropoulos, K.; Riegler, H. Hybrid Solution/VacuumProcessed Bilayer Heterojunction Organic Solar Cells: Structural Characterization and Performance. Thin Solid Films 2012, 525, 177-181.

(30) Na, S. I.; Wang, G.; Kim, S. S.; Kim, T. W.; Oh, S. H.; Yu, B. K.; Lee, T.; Kim, D. Y. Evolution of Nanomorphology and Anisotropic Conductivity in Solvent-Modified Pedot:Pss Films for Polymeric Anodes of Polymer Solar Cells. J. Mater. Chem. 2009, 19 (47), 90459053.

(31) Yeo, J. S.; Yun, J. M.; Kim, D. Y.; Kim, S. S.; Na, S. I. Successive Solvent-Treated Pedot:Pss Electrodes for Flexible Ito-Free Organic Photovoltaics. Sol. Energ. Mat. Sol. C. 2013, 114, 104-109.

(32) Kim, Y. H.; Sachse, C.; Machala, M. L.; May, C.; Muller-Meskamp, L.; Leo, K. Highly Conductive Pedot:Pss Electrode with Optimized Solvent and Thermal Post-Treatment for Ito-Free Organic Solar Cells. Adv. Funct. Mater. 2011, 21 (6), 1076-1081.

(33) Zhang, K.; Hu, Z. C.; Duan, C. H.; Ying, L.; Huang, F.; Cao, Y. The Effect of Methanol Treatment on the Performance of Polymer Solar Cells. Nanotechnology 2013, 24 (48).

(34) Singh, S. P.; Kumar, C. H. P.; Nagarjuna, P.; Sharma, G. D.; Biswas, S.; Mikroyannidis, J. A. Diarylmethanofullerene: Efficient Polymer Solar Cells with Low-BandGap Copolymer. J. Phys. Chem. C 2013, 117 (26), 13350-13356. 
(35) Wilken, S.; Hoffmann, T.; von Hauff, E.; Borchert, H.; Parisi, J. ITO-Free Inverted Polymer/Fullerene Solar Cells: Interface Effects and Comparison of Different SemiTransparent Front Contacts. Sol. Energ. Mat. Sol. C. 2012, 96 (1), 141-147.

(36) Hains, A. W.; Liu, J.; Martinson, A. B. F.; Irwin, M. D.; Marks, T. J. Anode Interfacial Tuning Via Electron-Blocking/Hole-Transport Layers and Indium Tin Oxide Surface Treatment in Bulk-Heterojunction Organic Photovoltaic Cells. Adv. Funct. Mater. 2010, 20 (4), 595-606.

(37) Heier, J.; Groenewold, J.; Huber, S.; Nueesch, F.; Hany, R. Nanoscale Structuring of Semiconducting Molecular Blend Films in the Presence of Mobile Counterions. Langmuir 2008, 24 (14), 7316-7322.

(38) Wicht, G.; Bucheler, S.; Dietrich, M.; Jager, T.; Nuesch, F.; Offermans, T.; Tisserant, J. N.; Wang, L.; Zhang, H.; Hany, R. Stability of Bilayer Trimethine Cyanine Dye/Fullerene Organic Solar Cells. Sol. Energ. Mat. Sol. C. 2013, 117, 585-591.

(39) Malinkiewicz, O.; Grancha, T.; Molina-Ontoria, A.; Soriano, A.; Brine, H.; Bolink, H. J. Efficient, Cyanine Dye Based Bilayer Solar Cells. Adv.Energ. Mater. 2013, 3 (4), 472-477. (40) Fan, B.; de Castro, F. A.; Heier, J.; Hany, R.; Nuesch, F. High Performing Doped Cyanine Bilayer Solar Cell. Org. Electron. 2010, 11 (4), 583-588.

(41) Kroger, M.; Hamwi, S.; Meyer, J.; Riedl, T.; Kowalsky, W.; Kahn, A. Role of the Deep-Lying Electronic States of Moo3 in the Enhancement of Hole-Injection in Organic Thin Films. Appl. Phys.Lett. 2009, 95 (12), 123301.

(42) Juska, G.; Viliunas, M.; Arlauskas, K.; Nekrasas, N.; Wyrsch, N.; Feitknecht, L. Hole Drift Mobility in Mu C-Si : H. J. Appl. Phys. 2001, 89 (9), 4971-4974.

(43) Juska, G.; Arlauskas, K.; Viliunas, M.; Kocka, J. Extraction Current Transients: New Method of Study of Charge Transport in Microcrystalline Silicon. Phys. Rev. Lett. 2000, 84 (21), 4946-4949.

(44) PAIOS by Fluxim AG, www.fluxim.com. 
(45) Semiconducting thin film optics simulator (SETFOS) by Fluxim AG, www.fluxim.com.

(46) Neukom, M. T.; Zufle, S.; Ruhstaller, B. Reliable Extraction of Organic Solar Cell Parameters by Combining Steady-State and Transient Techniques. Org. Electron. 2012, 13 (12), 2910-2916.

(47) Eklund, P. C.; Rao, A. M.; Wang, Y.; Zhou, P.; Wang, K. A.; Holden, J. M.; Dresselhaus, M. S.; Dresselhaus, G. Optical-Properties of C-60-Based and C-70-Based Solid Films. Thin Solid Films 1995, 257 (2), 211-232.

(48) Neukom, M. T.; Reinke, N. A.; Ruhstaller, B. Charge Extraction with Linearly Increasing Voltage: A Numerical Model for Parameter Extraction. Sol. Energy 2011, 85 (6), $1250-1256$.

(49) Singh, T. B.; Marjanovic, N.; Matt, G. J.; Gunes, S.; Sariciftci, N. S.; Ramil, A. M.; Andreev, A.; Sitter, H.; Schwodiauer, R.; Bauer, S. High-Mobility N-Channel Organic FieldEffect Transistors Based on Epitaxially Grown C-60 Films. Org. Electron. 2005, 6 (3), $105-$ 110.

(50) Anthopoulos, T. D.; Singh, B.; Marjanovic, N.; Sariciftci, N. S.; Ramil, A. M.; Sitter, H.; Colle, M.; de Leeuw, D. M. High Performance N-Channel Organic Field-Effect Transistors and Ring Oscillators Based on C-60 Fullerene Films. Appl. Phys. Lett. 2006, 89 (21).

(51) Rand, B. P.; Xue, J. G.; Uchida, S.; Forrest, S. R. Mixed Donor-Acceptor Molecular Heterojunctions for Photovoltaic Applications. I. Material Properties. J. Appl. Phys. 2005, 98

(52) Adam, G.; Pivrikas, A.; Ramil, A. M.; Tadesse, S.; Yohannes, T.; Sariciftci, N. S.; Egbe, D. A. M. Mobility and Photovoltaic Performance Studies on Polymer Blends: Effects of Side Chains Volume Fraction. J. Mat. Chem. 2011, 21 (8), 2594-2600. 
(53) Homa, B.; Andersson, M.; Inganas, O. Photogenerated Charge Carrier Transport and Recombination in Polyfluorene/Fullerene Bilayer and Blend Photovoltaic Devices. Org. Electron. 2009, 10 (3), 501-505.

(54) Tress, W.; Petrich, A.; Hummert, M.; Hein, M.; Leo, K.; Riede, M. Imbalanced Mobilities Causing S-Shaped Iv Curves in Planar Heterojunction Organic Solar Cells. Appl. Phys. Lett. 2011, 98 (6), 063301.

(55) Stickler, B. A.; Gruber, M.; Trimmel, G.; Schuerrer, F.; Zojer, K. Influence of Transport-Related Material Parameters on the I-V Characteristic of Inorganic-Organic Hybrid Solar Cells. Org. Electron. 2011, 12 (8), 1434-1445.

(56) Tress, W.; Leo, K.; Riede, M. Influence of Hole-Transport Layers and Donor Materials on Open-Circuit Voltage and Shape of I-V Curves of Organic Solar Cells. Adv. Funct. Mater. 2011, 21 (11), 2140-2149.

(57) Finck, B. Y.; Schwartz, B. J. Understanding the Origin of the S-Curve in Conjugated Polymer/Fullerene Photovoltaics from Drift-Diffusion Simulations. Appl. Phys. Lett. 2013, $103(5), 053306$.

(58) Schulze, K.; Uhrich, C.; Schuppel, R.; Leo, K.; Pfeiffer, M.; Brier, E.; Reinold, E.; Bauerle, P. Efficient Vacuum-Deposited Organic Solar Cells Based on a New Low-Bandgap Oligothiophene and Fullerene C-60. Adv. Mater. 2006, 18 (21), 2872- 2875.

(59) de Castro, F. A.; Heier, J.; Nuesch, F.; Hany, R. Origin of the Kink in Current-Density Versus Voltage Curves and Efficiency Enhancement of Polymer-C-60 Heterojunction Solar Cells. IEEE J. Sel. Top. Quant. 2010, 16 (6), 1690-1699.

(60) Wagner, J.; Gruber, M.; Wilke, A.; Tanaka, Y.; Topczak, K.; Steindamm, A.; Hoermann, U.; Opitz, A.; Nakayama, Y.; Ishii, H.; Pflaum, J.; Koch, N.; Bruetting, W. Identification of Different Origins for S-Shaped Current Voltage Characteristics in Planar Heterojunction Organic Solar Cells. J. Appl. Phys. 2012, 111 (5), 054509. 
(61) Berner, E.; Jaeger, T.; Lanz, T.; Nueesch, F.; Tisserant, J.-N.; Wicht, G.; Zhang, H.; Hany, R. Influence of Crystalline Titanium Oxide Layer Smoothness on the Performance of Inverted Organic Bilayer Solar Cells. Appl. Phys. Lett. 2013, 102 (18), 183903.

(62) Lee, K. H.; Zhang, Y.; Burn, P. L.; Gentle, I. R.; James, M.; Nelson, A.; Meredith, P. Correlation of Diffusion and Performance in Sequentially Processed P3HT/PCBM Heterojunction Films by Time-Resolved Neutron Reflectometry. J. Mater. Chem. C 2013, 1 (14), 2593-2598.

(63) Tezuka, Y.; Yamamoto, T.; Kamikado, Y.; Tanaka, H. Partially Interpenetrating Heterojunction on Bilayer Photovoltaic Devices of Electrodeposited Polythiophene/Methanofullerene. Sol. Energ. Mat. Sol. C. 2012, 105, 167-173.

(64) Wong, M. K.; Wong, K. Y., Investigation of the Factors Affecting the Power Conversion Efficiency of All-Solution-Processed 'Bilayer' P3HT:PCBM Solar Cells. Synthetic Metals 2013, 170, 1-6.

(65) Nowy, S.; Ren, W.; Elschner, A.; Lovenich, W.; Brutting, W. Impedance Spectroscopy as a Probe for the Degradation of Organic Light-Emitting Diodes. J. Appl. Phys. 2010, 107 (5), 054501.

(66) Chary, K. V. R.; Bhaskar, T.; Seela, K. K.; Lakshmi, K. S.; Reddy, K. R. Characterization and Reactivity of Molybdenum Oxide Catalysts Supported on Anatase and Rutile Polymorphs of Titania. Appl. Cat. A-Gen. 2001, 208 (1-2), 291-305.

(67) Gaigneaux, E. M.; Genet, M. J.; Ruiz, P.; Delmon, B. Catalytic Behavior of Molybdenum Suboxides in the Selective Oxidation of Isobutene to Methacrolein. J. Phys. Chem. B 2000, 104 (24), 5724-5737.

(68) Hu, H. C.; Wachs, I. E.; Bare, S. R. Surface-Structures of Supported Molybdenum Oxide Catalysts - Characterization by Raman and Mo L(3)-Edge Xanes. J. Phys. Chem. 1995, 99 (27), 10897-10910. 
(69) Seo, J. H.; Gutacker, A.; Sun, Y.; Wu, H.; Huang, F.; Cao, Y.; Scherf, U.; Heeger, A.

J.; Bazan, G. C. Improved High-Efficiency Organic Solar Cells Via Incorporation of a Conjugated Polyelectrolyte Interlayer. J. Am. Chem. Soc. 2011, 133 (22), 8416-8419.

(70) Tatikolov, A. S.; Ishchenko, A. A.; Ghelli, S.; Ponterini, G. Ion Pairs of Indobenzimidazolo Cyanines: A Structural Study Based on Conductivity, Absorption, Fluorescence and H-1-NMR. J. Mol. Struct. 1998, 471 (1-3), 145-159.

(71) Chang, L. L.; Lademann, H. W. A.; Bonekamp, J. B.; Meerholz, K.; Moule, A. J. Effect of Trace Solvent on the Morphology of P3HT:PCBM Bulk Heterojunction Solar Cells. Adv. Funct. Mater. 2011, 21 (10), 1779-1787.

(72) Hany, R., private communication.

(73) Tanaka, Y.; Xiao, Y. F.; Matsuo, S. Relative Permittivity of Fluoroalcohols at Temperatures from 293 to $323 \mathrm{~K}$ and Pressures up to $50 \mathrm{MPa}$. Fluid Phase Equilibr. 2000, $170(1), 139-149$.

(74) Scott, J. C.; Malliaras, G. G., Charge Injection and Recombination at the MetalOrganic Interface. Chem. Phys. Lett. 1999, 299 (2), 115-119. 
GRAPHICAL ABSTRACT

\section{Abstract figure}

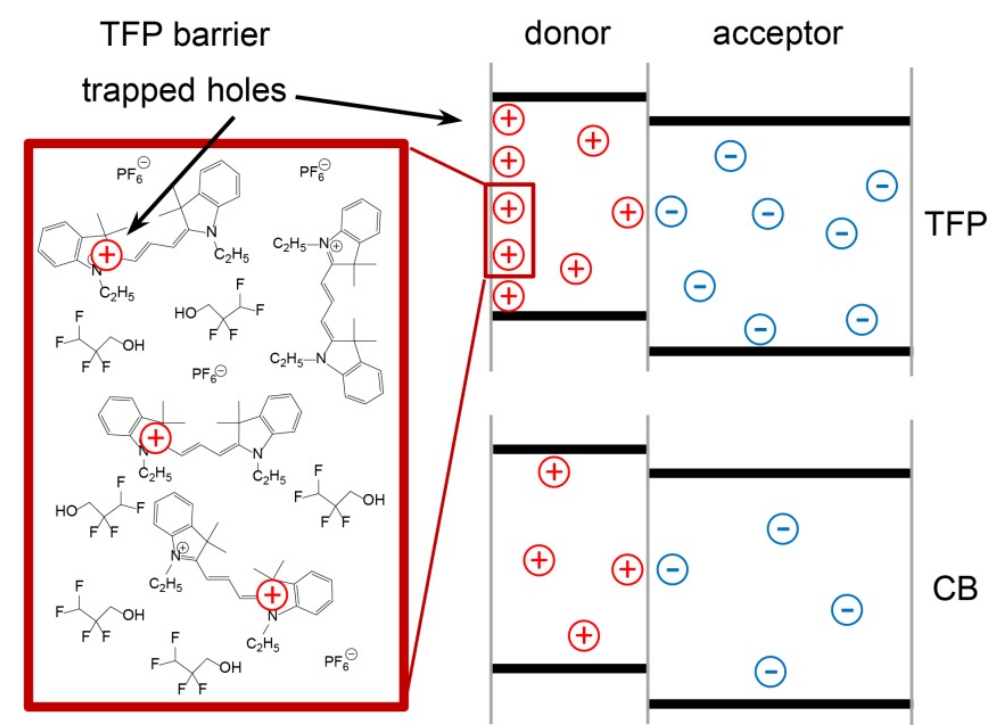

